\title{
Effect of the chemical vapor deposition condition on the electrochemically catalytic efficiency for hydrogen evolution reaction in $\mathrm{MoS}_{2}$ nanoparticles
}

\author{
Quyen Le Do, Duc Anh Nguyen*
}

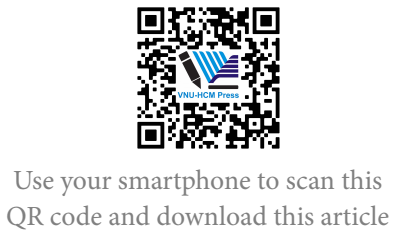

\begin{abstract}
Introduction: Using the metal organic chemical vapor deposition (MOCVD) method, we have synthesized the $\mathrm{MoS}_{2}$ nanoparticles on graphite foil substrates employed as the electrochemical working electrodes with highly efficient electrocatalysis for hydrogen evolution reaction (HER). Methods: The morphological and structural properties of the as-grown $\mathrm{MoS}_{2}$ materials were demonstrated by field emission scanning electron microscope (FESEM) and Raman spectroscopies, while their elemental components were investigated by X-ray photoelectron spectroscopy (XPS). Results: The optimum growth time was acquired to be 11 hours. Thereby such obtained electrode exhibited the maximum HER activity with onset over the potential of $220 \mathrm{mV}$ versus reversible hydrogen electrode (RHE), and the Tafel slope of $66 \mathrm{mV}$ per decade $(\mathrm{mV} / \mathrm{dec})$. Conclusion: Our results suggest a good technique for the research of high-efficient HER electrocatalyst based on atomicthickness layered materials.
\end{abstract}

Key words: MoS2 nanoparticles, metal-organic chemical vapor deposition, hydrogen evolution reaction

Department of Physics, Faculty of Basic-Fundamental Sciences, Viet Nam Maritime University, 484 Lach Tray Road, Le Chan, Hai Phong, Viet Nam.

Correspondence

Duc Anh Nguyen, Department of Physics, Faculty of Basic-Fundamental Sciences, Viet Nam Maritime University, 484 Lach Tray Road, Le Chan, Hai Phong, Viet Nam

Email: ducna@vimaru.edu.vn

\section{History}

- Received: 2021-02-21

- Accepted: 2021-05-05

- Published: 2021-05-13

DOI : 10.32508/stdj.v24i2.2520

\section{Check for updates}

\section{Copyright}

(c) VNU-HCM Press. This is an openaccess article distributed under the terms of the Creative Commons Attribution 4.0 International license.

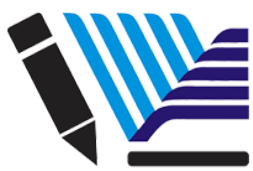

VNU-HCM Press

ity of $\mathrm{MoS}_{2}$. These efforts can be the growth of ver-

\section{INTRODUCTION}

Hydrogen gas, an excellent source of clean energy, has been demonstrated as an ideal replacement for hydrocarbon-based and fossil fuels ${ }^{1,2}$. Hydrogen gas can be conveniently yielded from the electrochemical water splitting reaction ${ }^{2-4}$. Using this approach, the hydrogen evolution reaction (HER) that happens on a cathode surface can be accelerated by loading an electrocatalyst on it. However, the best electrocatalysts for HER are Pt and its relation noble metals, which has substantially limited their commercial massive production $^{4-6}$. Thus, developing low-cost electrocatalysts that possess strong stable and HER performance to be close to Pt-based catalysts is ultimately desirable. So far, nanostructures of molybdenum disulfide $\left(\mathrm{MoS}_{2}\right)$ have been proven promising candidates for excellent catalytic activity ${ }^{7-9}$. Using DFT calculation, J. K. Nørskov's group first reported that hydrogen adsorption Gibbs free energy of edge sites of $\mathrm{MoS}_{2}$ is close to zero $\left(\Delta \mathrm{G}_{H} \sim 0 \mathrm{eV}\right)$, suggesting $\mathrm{MoS}_{2}$ probably as a great HER catalyst ${ }^{10}$. The experimental measurements then assured this prediction of HER performance of $\mathrm{MoS}_{2}$ nanoparticles on graphite ${ }^{10}$, and $\mathrm{Au}(111)$ substrates ${ }^{11}$. Subsequently, numerous reports have focused on maximizing the exposured active-edge-sites, arming to enhance the HER activ- tical nanoflakes ${ }^{12}$, nanobelts ${ }^{13}$, mesoporous ${ }^{14,15}$, or nanoparticles ${ }^{16}$. On the other hand, due to low intrinsic conductivity in $\mathrm{MoS}_{2}$, one can reduce the number of layers to minimum the charge transfer resistance between the exposure surface at the outmost layer and the electrode ${ }^{17}$. In this regard, a small number of layers was demonstrated as another important expect for highly catalytic HER performance in $\mathrm{MoS}_{2}$ nanostructure. Generally, $\mathrm{MoS}_{2}$ nanostructure with a small number of layers (around 2 4 layers) might be a great alternative of noble-metal-based HER electrocatalysts. However, synthesis a large scale of few-layer $\mathrm{MoS}_{2}$ nanostructure directly on conductive substantial has been still difficult ${ }^{18}$.

Here, we used the MOCVD technique to grow $\mathrm{MoS}_{2}$ nanoparticles directly on conductive graphite, which was applied for HER electrochemical working electrode. This work focused on the dependence of HER performance on the MOCVD growing condition, particularly the growth time. We found the sample grown in $11 \mathrm{~h}$ to exhibit the highest HER activity with the smallest onset overpotential of $250 \mathrm{mV} / \mathrm{dec}$, and the Tafel slope of $66 \mathrm{mV} / \mathrm{dec}$.

\section{MATERIALS - METHODS}

Cite this article : Do Q L, Nguyen D A. Effect of the chemical vapor deposition condition on the electrochemically catalytic efficiency for hydrogen evolution reaction in $\mathbf{M o S}_{2}$ nanoparticles. Sci. Tech. Dev. J.; 24(2):1947-1953. 


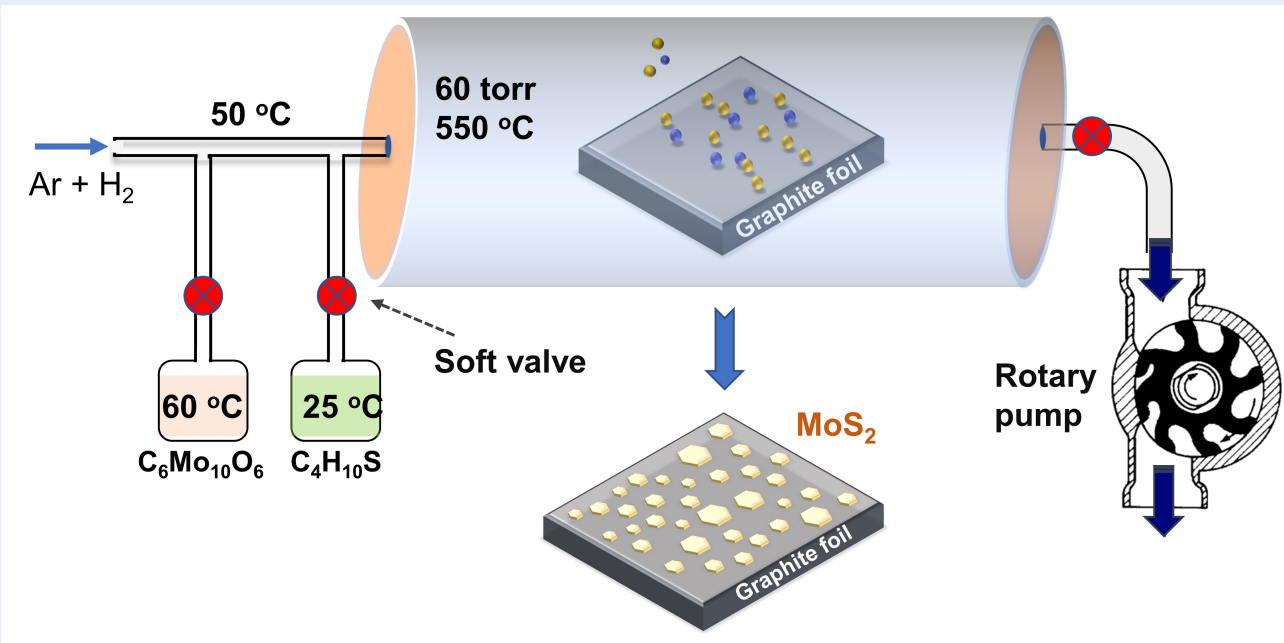

Figure 1: Schematic illustrationof MOCVD system growing $\mathrm{MoS}_{2}$ nanoparticles.

\section{Synthesis of $\mathrm{MoS}_{2}$ nanoparticles}

$\mathrm{MoS}_{2}$ nanoparticles were synthesized via MOCVD, as schematically illustrated in Figure 1. Briefly, the experiment was taken place in a sealed 1-inch diameter quartz tube, and then graphite foil electrodes were placed at the center of the heated zone. The metal-organic compound of molybdenum hexacarbonyl (MHC, $\mathrm{C}_{6} \mathrm{MoO}_{6}$ ) and diethyl sulfide (DES, $\mathrm{C}_{4} \mathrm{H}_{10} \mathrm{~S}$ ) have high equilibrium vapor pressure were used as the gaseous precursors. Firstly, the base vacuum ( 1 mtorr) was established in the chamber by a rotary pump. At the same time, the temperature of $\mathrm{MHC}$ and DES bearer was adapted at $25^{\circ} \mathrm{C}$ and $60^{\circ} \mathrm{C}$, respectively. Then, a flow of 1 standard cubic centimeter per minute ( $\mathrm{sccm}$ ) of Ar gas was injected into DES bearer to dilution and thus facilitated the DES vapor flow. The temperature of the carrier line was fixed at $50{ }^{\circ} \mathrm{C}$, and that of the reaction zone was $550^{\circ} \mathrm{C}$. A mixture of $30 \mathrm{sccm}$ of Ar and $5 \mathrm{sccm}$ of $\mathrm{H}_{2}$ was continuously flowed into the reaction chamber during all growing processes to maintain the working pressure to be 60 torrs. Subsequently, the reaction process was started by introducing $1 \mathrm{sccm}$ mix of (Ar $+\mathrm{DES})$ and open soft valve of the MHC holder. For a comparative investigation of HER reactivity, $\mathrm{MoS}_{2}$ samples were synthesized with various deposition times of 7 , $9,11,13 \mathrm{~h}$ by a similar deposition condition.

\section{Characterization}

The morphology of $\mathrm{MoS}_{2}$ samples was characterized by field-emission scanning electron microscopy (JSM-6500F, JEOL). The lattice vibrational properties were investigated by micro-Raman spectroscopy using a $473 \mathrm{~nm}$ excitation source under ambient conditions. The X-ray photoelectron spectroscopy (XPS) measurements were carried out using a Theta Prove AR-XPS System (Thermo Fisher Scientific).

\section{HER measurements}

The three electrodes configuration, including graphite rod (i.e., counter electrode), $\mathrm{Ag} / \mathrm{AgCl}$ (i.e., reference electrode), and $\mathrm{MoS}_{2}$ nanoparticles on graphite foil (i.e., working electrode) was employed to plot the linear sweep voltammetry (LSV) and cyclic voltammetry $(\mathrm{CV})$. All the electrochemical measurement was put in a $0.5 \mathrm{M} \mathrm{H}_{2} \mathrm{SO}_{4}$ electrolyte and was established in an electrochemical workstation (IviumStat, Ivium Tech) to study the HER reactivity.

\section{RESULTS}

The morphology of $\mathrm{MoS}_{2}$ nanoparticles was observed by FESEM images, as shown in Figure 2. As shown in Figure $2 \mathrm{a}$ and $\mathrm{b}$, the $6 \mathrm{~h}$ grown sample is similar to the blank substrate, indicating that before $6 \mathrm{~h}$, the $\mathrm{MoS}_{2}$ has not been formed in the substrate. When the growth time reaches $7 \mathrm{~h}$ (Figure $2 \mathrm{c}$ ), tiny particles appear with the size of 50-100 nm. According to Figure $2 \mathrm{~d}-\mathrm{f}$, the density of the nanoparticles increased with the growth time, while the size of particles seems to be not changed.

Figure 3 shows the Raman spectra of the obtained $\mathrm{MoS}_{2}$ samples. As shown in Figure 3a, two peaks located at 378.2 and 401.5 are attributed to the two typical active Raman scattering mode of $\mathrm{E}^{1} 2 g$ and $\mathrm{A}_{1 g}$ vibrational modes in $2 \mathrm{H}$ phase of $\mathrm{MoS}_{2}$, in which the 


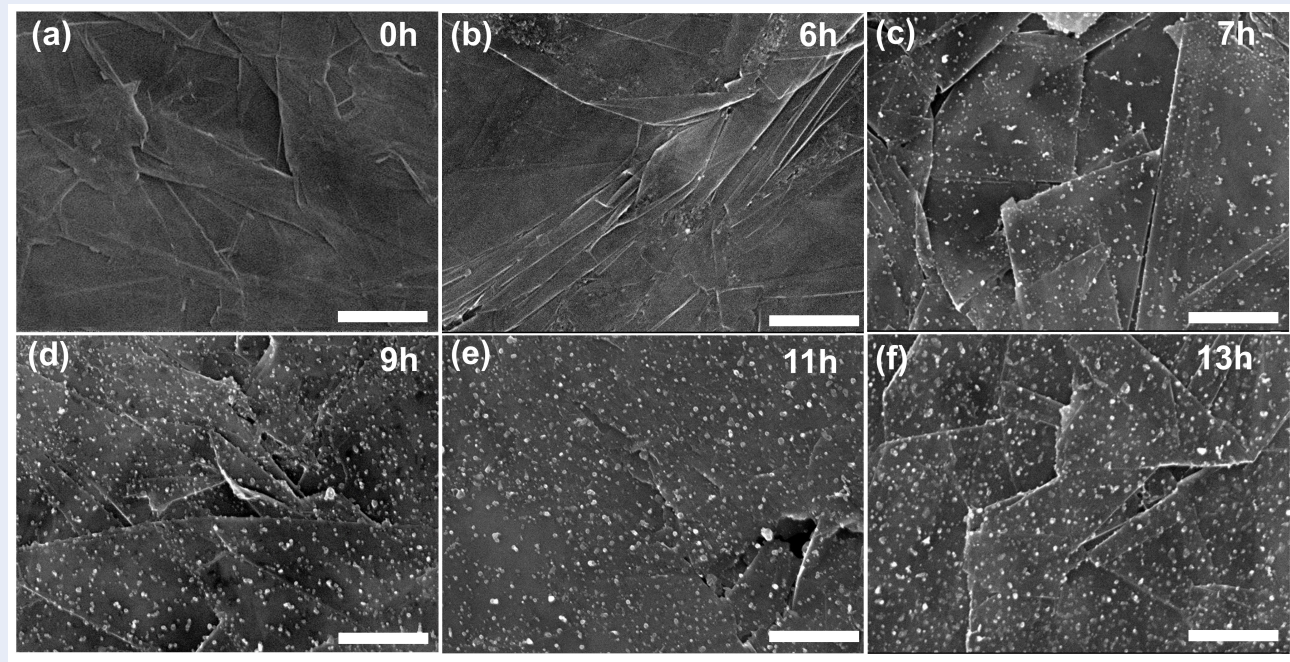

Figure 2: Morphological analysis. FESEM images of baregraphite foil (a), and $\mathrm{MoS}_{2}$ nanoparticles (b-f) synthesized for $6,7,9,11,13 \mathrm{~h}$. The scale bar is $1 \mu \mathrm{m}$.
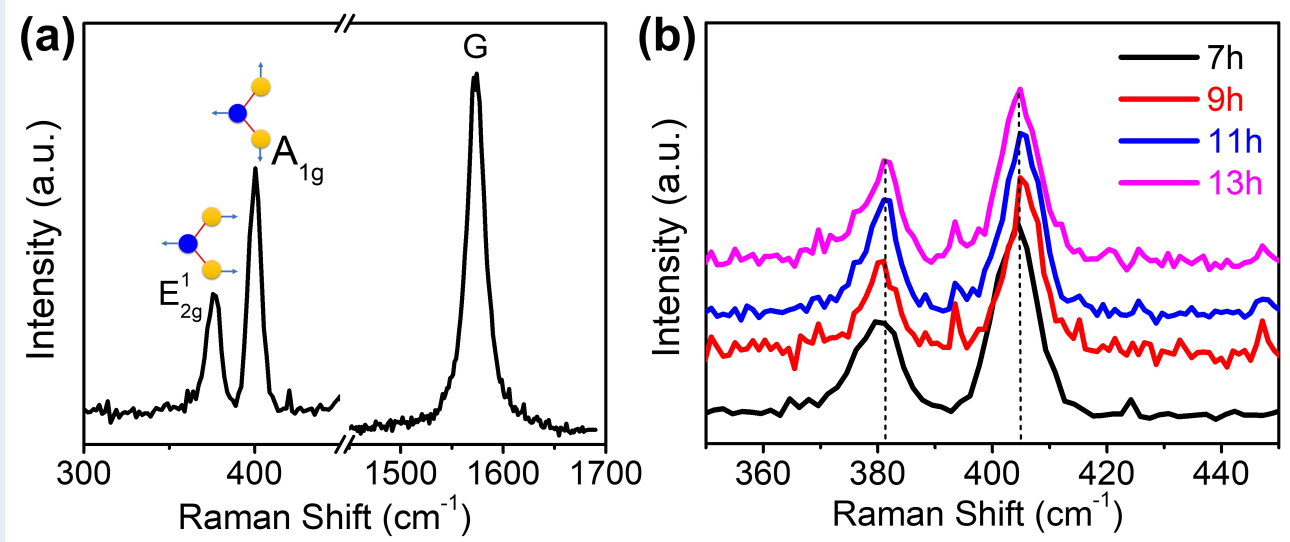

Figure 3: Raman spectra of $\operatorname{MoS}_{2}$ nanoparticles ongraphite substrate (a). The zoom-in of the Raman spectra of samples grown in $7 \mathrm{hto} 13 \mathrm{~h}$.

first one $\left(\mathrm{E}_{2 g}^{1}\right)$ is attributed to the in-plane vibration of Mo-S bond, while the other one $\left(\mathrm{A}_{1 g}\right)$ is corresponding to the out-of-plane vibration of $\mathrm{S}$ atoms ${ }^{19}$. Moreover, the frequency separation between these two peaks of $23.5 \mathrm{~cm}^{-1}$ suggested that the number of layers was between 3 and 4 layers ${ }^{17,20}$. Although the growth time is much different (alternating between $7 \mathrm{~h} \sim 1 \mathrm{~h}$ ), the number of layers of samples does not change, reflected by the non-shift in the Raman peaks position (Figure 3b).

The X-ray photoelectron spectroscopy (see Figure 4ab) was constructed to study the elemental bonding states of as-grown $\mathrm{MoS}_{2}$ nanoparticles. Figure 4a illustrated the high-resolution of XPS spectra in Mo
$3 \mathrm{~d}$ region. As can be seen, the two olive-fitted peaks located at 229.65 and $232.8 \mathrm{eV}$ are corresponding to $\mathrm{Mo}^{4+} 3 \mathrm{~d}_{5 / 2}$ and $\mathrm{Mo}^{4+} 3 \mathrm{~d}_{3 / 2}$ energy levels in $\mathrm{MoS}_{2}$, respectively ${ }^{21}$. Besides, the two small peaks (orange fitted curves) overbed at 231.8, and $235.9 \mathrm{eV}$ are ascribed to the $\mathrm{Mo}^{6+}$ states, indicating the formation of a small amount of molybdenum oxide due to partial oxidation of MHC throughout the deposition process $^{22,23}$. Additionally, two blue fitted peaks that were detected at 162.5 and $163.7 \mathrm{eV}$ (see Figure $4 \mathrm{~b}$ ) are attributed to the $S^{2-} 2 p_{3 / 2}$ and $S^{2-} 2 p_{1 / 2}$ energy states in $\mathrm{MoS}_{2}$, respectively ${ }^{23}$. Thus, all these data confirmed the chemical elemental composition of the fabricated materials. 

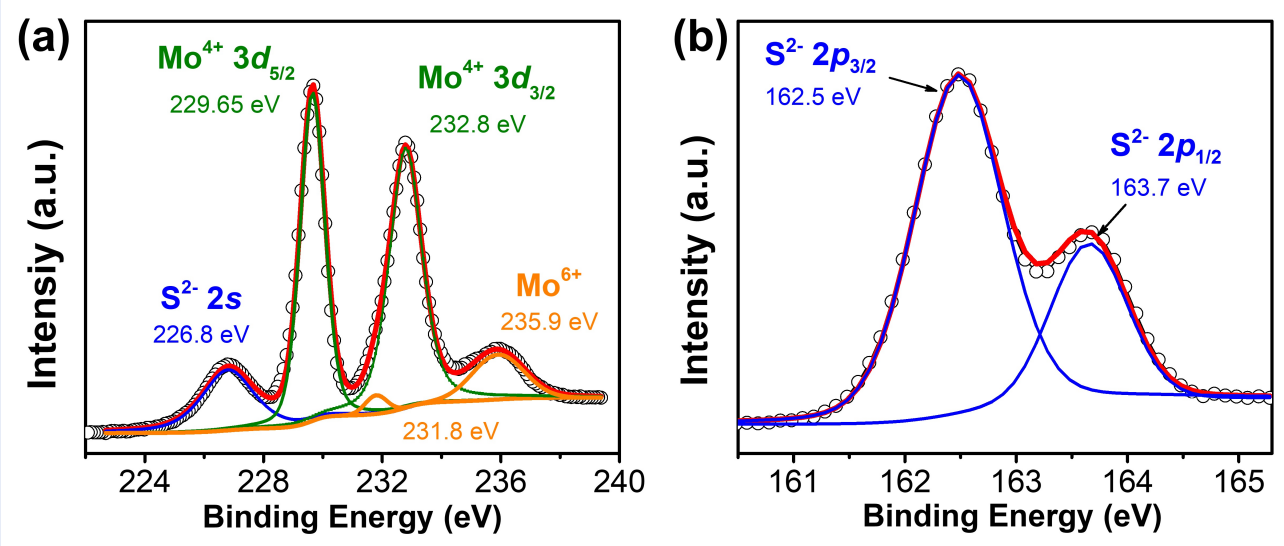

Figure 4: Chemical composition analysis. The high-resolution XPS spectroscopy of as-grown $\mathrm{MoS}_{2}$ nanoparticles superimposed by fits(red lines) for (a) Mo 3d energy levels range: $\mathrm{Mo}^{4+}$ (olive trace),and $\mathrm{Mo}^{6+}$ (orange trace); (b) $S 2 p$ energy levels range: $S^{2-}$ of $M_{0} S_{2}$ (blue trace).

The HER performance was firstly examined by the linear sweep voltammetry (i.e., polarization curves), as illustrated in Figure 5a. As can be seen, there was a considerable enhance of HER activity as the CVD growth time increase from $7 \mathrm{~h}$ to $11 \mathrm{~h}$. The $11 \mathrm{~h}$ sample revealed the highest performance with the onset overpotential of approximately $250 \mathrm{mV}$ vs. RHE, which was considerably smaller than the $7 \mathrm{~h}, 13 \mathrm{~h}$, and bare samples. The Tafel plots can also be used to evaluate the electrocatalytic activity for HER, in which the smaller obtained Tafel slope corresponds to the higher HER reactivity. Figure 5b exhibited the corresponding Tafel plots of the $\mathrm{MoS}_{2}$ nanoparticles synthesized at different times. Even though the $9 \mathrm{~h}$ sample exhibited a similar onset overpotential with the $11 \mathrm{~h}$ sample, its Tafel slope of $91 \mathrm{mV} / \mathrm{dec}$ was much higher than that of the $11 \mathrm{~h}$ sample $(66 \mathrm{mV} / \mathrm{dec})$. However, when we further expanded the deposition time until $13 \mathrm{~h}$, the performance experienced a degeneration with the onset overpotential and the corresponding Tafel slope enlarged to $\sim 350 \mathrm{mV}$ vs. RHE and $88 \mathrm{mV} / \mathrm{dec}$, respectively. Generally, the $\mathrm{MoS}_{2}$ nanoparticles deposited in $11 \mathrm{~h}$ exhibited the optimum electrochemically catalytic activity for HER.

To evaluate the density of the active site of catalysts, the cyclic voltammetry (CV) plots in a nonFaradic potential range were conducted at the scan rates changing between 10 and $70 \mathrm{mV} / \mathrm{s}$, as shown in Figure $5 \mathrm{c}$. Then, the double-layer capacitance $\left(\mathrm{C}_{d l}\right)$ obtained from the linear fitting the dependance of the average current density versus scan rates (Figure $5 \mathrm{~d}$ ) was demonstrated to be proportional to the active site density ${ }^{24}$. As can be seen, the $11 \mathrm{~h}$ sample exhibited the maximum $\mathrm{C}_{d l}$ of $2.21 \mathrm{mF} / \mathrm{cm}^{2}$, which is considerably larger than that of the rest ones. Thus, although the morphology and the density of $\mathrm{MoS}_{2}$ nanoparticles of $11 \mathrm{~h}$ and $13 \mathrm{~h}$ samples are almost similar, the former reveals a significantly higher performance than the latter. Nevertheless, these calculations of the electrochemically active surface area of catalysts were well consistent with the above polarization curves.

Finally, the stability test for the HER catalytic activity of $11 \mathrm{~h}$ sample was investigated by the transient chronopotentiometry measurement with a working current density of $-5 \mathrm{~mA} / \mathrm{cm}^{2}$, as depicted in Figure 5 e. During a period of $20 \mathrm{~h}$, we observed no significant variation of overpotential, demonstrating great stability. In addition, the nominal modification of polarization curves before and after the durability characterization verified the superior working stability of as-obtained $\mathrm{MoS}_{2}$ nanoparticles (Figure 5f).

\section{DISCUSSION}

As mentioned, the $\mathrm{MoS}_{2}$ nanoparticles that recently have been considered as a promising candidate for highly efficient electrocatalytic for HER were fabricated. Remarkably, our MOCVD method supported a direct growth of $\mathrm{MoS}_{2}$ nanoparticles on conductive graphite foil electrodes which simplified the material preparation. The electrode surficial phenomena were tested without any extra transfer process. In this way, it also naturally avoided the electrical loss contacts for the electrochemical measurements. For catalytic HER activity, the electrochemically active sites play an essential role. Frequently, the active sites locate at the edge-sites rather than at the basal plane. As a result, 


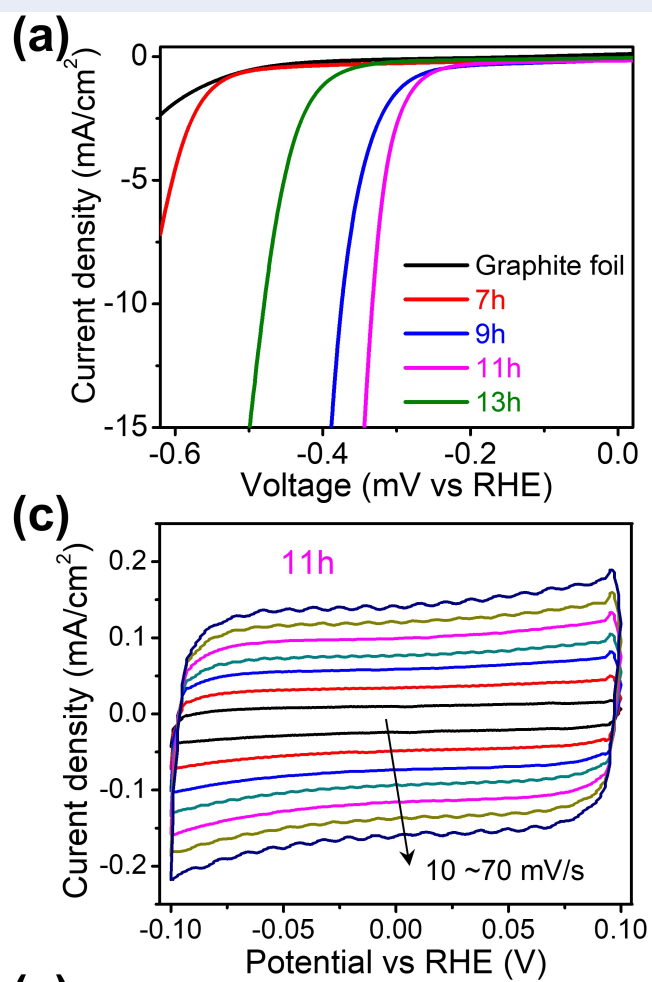

(e)

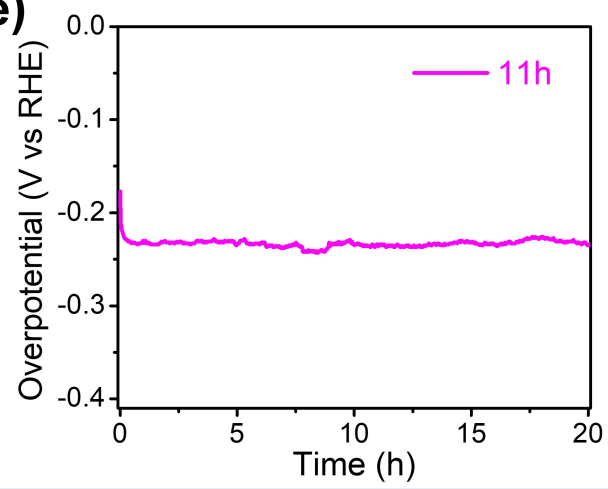

(b)
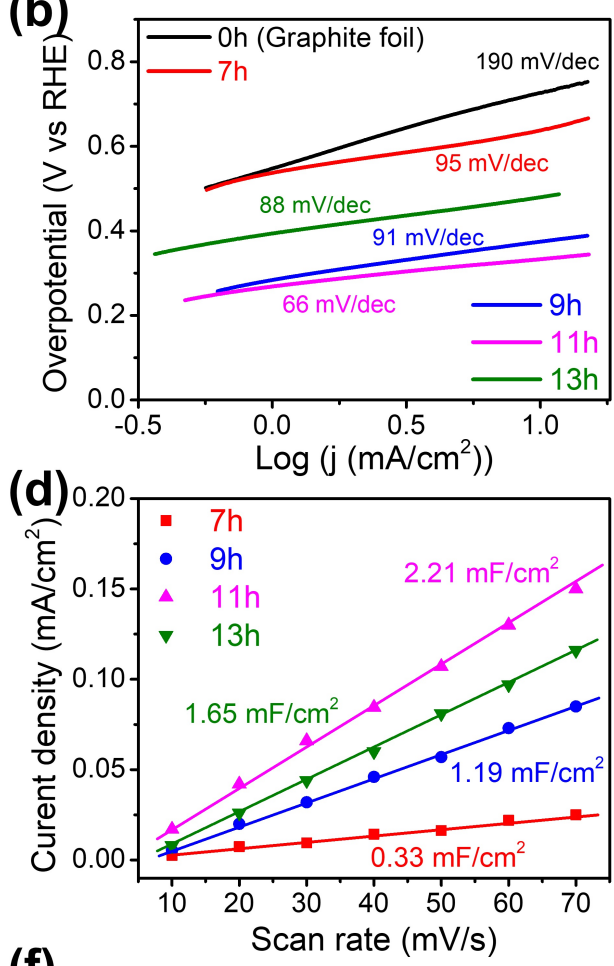

(f)

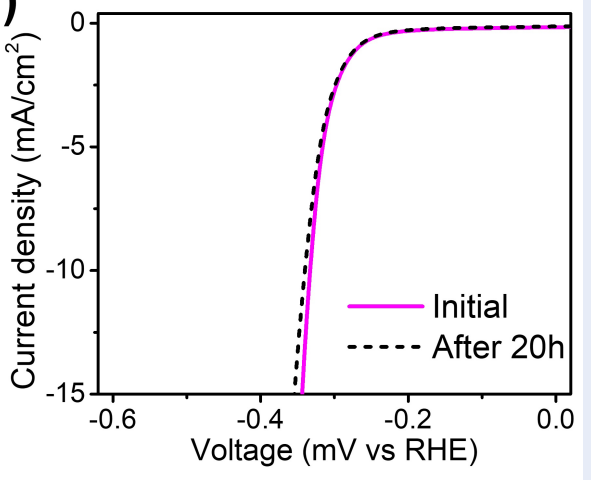

Figure 5: Electrocatalytic HER activities of $\mathbf{M o S}_{2}$ nanoparticles. (a, b) iR-corrected LSVs and Tafel plots, respectively. (c, d) Cyclic voltammetry of the $11 \mathrm{~h}$ sample at various scan rate, and the linearfitting of the average capacitive current density versus the scan rate for $\mathrm{MoS}_{2}$ sample with different growth time, respectively. Stability of the obtained $\mathrm{MoS}_{2}$ sample, (e) Potential vs. time plot, conducted at $-5 \mathrm{~mA} / \mathrm{cm}^{2}$ for 11 hsample, (f) LSVs of the initial $11 \mathrm{~h}$ sample (magenta) and after applying bias states (dashed black).

ragged particles in nanoscale size are more favorable than a uniform continuous film. In addition to the morphological aspects, the thickness of $\mathrm{MoS}_{2}$ material is another essential factor affecting total performance. The layer number ranging from 3 to 4 was demonstrated as the best option for HER reactivity ${ }^{16}$. Interestingly, the fabricated $\mathrm{MoS}_{2}$ particles in this work well matched with above requirements.

In this study, under the same reaction temperature, carrier gas concentration, and precursors' flow rate, the morphology (i.e. size and layer number) of $\mathrm{MoS}_{2}$ nanoparticles was similar; therefore, the catalytic activities essentially only depended on the density of particles. Meanwhile, the growth time leaded to the change of particle density. Thus, for the samples grown from 7 to $11 \mathrm{~h}$, a considerable enhancement in the electrocatalytic activity can be easily understood as extending the density of $\mathrm{MoS}_{2}$ nanoparticles. However, we assert that a further extending growth time ( $\geq 13 \mathrm{~h}$ ) should not be employed to acquire the optimum performance. We attributed the best HER performance of $11 \mathrm{~h}$ samples to the maximum of active 
site density compared to the other ones, which was then proved by the fact that it has the highest value of electrochemical double-layer capacitance $\left(C_{d l}\right)$. One possible reason for lower performance in the more extended growth sample was a transition from the electrochemical active-Mo-edge sites to the inert S-edge sites through extra growth time ${ }^{25}$. Such extra growth time might fulfill some S-vacancies existing near the active-Mo-edge sites. This mechanism should be further confirmed in the following research topic.

Finally, although the obtained performance of the present $\mathrm{MoS}_{2}$ sample was relatively better than that of some previous $\mathrm{MoS}_{2}$ based materials ${ }^{18,26}$, it has been still far from that of Pt-based catalysts (Tafel slope $\sim 30$ $\mathrm{mV} / \mathrm{dec})^{27}$. Therefore, some additional works are required to improve current results further. We suggest that the efficiency of $\mathrm{MoS}_{2}$ nanoparticles can be further enhanced by activating the basal plane of $\mathrm{MoS}_{2}$ nanoparticles by further applying surficial treatment routes, such as doping, engineering $\mathrm{S}$-vacancies defect positions or hybridization with a high-surfacearea substrate.

\section{CONCLUSION}

We have reported the method, namely MOCVD, to synthesize $\mathrm{MoS}_{2}$ nanoparticles applying for the HER electrocatalysis. We found that the deposition time considerably affected the HER efficiency in which the electrochemically active sites density played an essential factor. Particularly, the $11 \mathrm{~h}$ deposited $\mathrm{MoS}_{2}$ sample showed the highest active site density, thereby the best HER performance with onset overpotential of $250 \mathrm{mV}$ vs. RHE, and the Tafel slope of $66 \mathrm{mV} / \mathrm{dec}$. Thus, this search may provide a straightforward and convenient route to acquire a good replacement to the Pt-based electrocatalysts.

\section{ABBREVIATIONS}

MOCVD: Metal-organic Chemical Vapor Deposition

HER: Hydrogen Evolution Reaction

RHE: Reversible Hydrogen Electrode

MHC: Molybdenum Hexacarbonyl, $\mathrm{Mo}(\mathrm{CO})_{6}$

DES: Diethyl Sulfide, $\left(\mathrm{C}_{2} \mathrm{H}_{5}\right)_{2} \mathrm{~S}$

FESEM: Field Emission Scanning Electron Microscope

XPS: X-ray Photoelectron Spectroscopy

LSV: Linear Sweep Voltammetry

CV: Cyclic Voltammetry

\section{COMPETING INTERESTS}

The authors declare no competing interests

\section{AUTHORS CONTRIBUTIONS}

Q. L. D designed and performed the experiments. D. A. $\mathrm{N}$ analyzed data and wrote the manuscript. All authors have given approval to the final version of the manuscript.

\section{ACKNOWLEDGMENTS}

This work is funded by Vietnam Maritime University under grant number: "DT20-21.94".

\section{REFERENCES}

1. Cortright RD, Davda RR, Dumesic JA. Hydrogen from Catalytic Reforming of Biomass-derived Hydrocarbons in Liquid Water. Nature. 2002;418:964-966. PMID: 12198544. Available from: https://doi.org/10.1038/nature01009.

2. Turner JA. Sustainable Hydrogen Production. Science. 2004;305:972-974. PMID: 15310892. Available from: https://doi.org/10.1126/science.1103197.

3. Schlapbach L, Züttel A. Hydrogen-storage Materials for Mobile Applications. Nature. 2001;414:353-358. PMID: 11713542. Available from: https://doi.org/10.1038/35104634.

4. Zhu J, Hu L, Zhao P, Lee LYS, Wong KY. Recent Advances in Electrocatalytic Hydrogen Evolution Using Nanoparticles. Chem. Rev. 2020;120:851-918. PMID: 31657904. Available from: https://doi.org/10.1021/acs.chemrev.9b00248.

5. Voiry D, Shin HS, Loh KP, Chhowalla M. Low-dimensional catalysts for hydrogen evolution and $\mathrm{CO} 2$ reduction. Nat. Rev. Chem. 2018;2:0105. Available from: https://doi.org/10.1038/ s41570-017-0105.

6. Zou X, Zhang Y. Noble metal-free hydrogen evolution catalysts for water splitting. Chem. Soc. Rev., 2015, 44, 514880;PMID: 25886650. Available from: https://doi.org/10.1039/ C4CS00448E.

7. Yang L, Liu P, Li J, Xiang B. Two-Dimensional Material Molybdenum Disulfides as Electrocatalysts for Hydrogen Evolution. Catalysts. 2017;7:1-18. Available from: https://doi.org/10. 3390/catal7100285.

8. Ding Q, Song B, Xu P, Jin S. Efficient Electrocatalytic and Photoelectrochemical Hydrogen Generation Using MoS2 and Related Compounds. Chem. 2016;1:699-726. Available from: https://doi.org/10.1016/j.chempr.2016.10.007.

9. Lu Q, Yu Y, Ma Q, Chen B, Zhang H. 2D Transition-MetalDichalcogenide-Nanosheet-Based Composites for Photocatalytic and Electrocatalytic Hydrogen Evolution Reactions. Adv. Mater. 2016;28:1917-1933. PMID: 26676800. Available from: https://doi.org/10.1002/adma.201503270.

10. Hinnemann B, Moses PG, Bonde J, Jørgensen KP, Nielsen $\mathrm{JH}$, Horch S, Chorkendorff I, Nørskov JK. Biomimetic Hydrogen Evolution: MoS2 Nanoparticles as Catalyst for Hydrogen Evolution. J. Am. Chem. Soc. 2005;127:5308-5309. PMID: 15826154. Available from: https://doi.org/10.1021/ja0504690.

11. Jaramillo TF, Jørgensen $K P$, Bonde J, Nielsen JH, Horch $S$, Chorkendorff I. Identification of Active Edge Sites for Electrochemical H2 Evolution from MoS2 Nanocatalysts. Science. 2007;137:100-102. PMID: 17615351. Available from: https: //doi.org/10.1126/science.1141483.

12. Kong D, Wang H, Cha JJ, Pasta M, Koski KJ, Yao J, Cui Y. Synthesis of MoS2 and MoSe2 Films with Vertically Aligned Layers. Nano Lett. 2013;13:1341-1347. PMID: 23387444. Available from: https://doi.org/10.1021/nl400258t.

13. Yang L, Hong $\mathrm{H}$, Fu Q, Huang $Y$, Zhang J, Cui X, Fan Z, Liu K, Xiang B. Single-Crystal Atomic-Layered Molybdenum Disulfide Nanobelts with High Surface Activity. ACS Nano, 2015, 9, 6478-6483;PMID: 26030397. Available from: https://doi.org/ 10.1021/acsnano.5b02188.

14. Kibsgaard J, Chen Z, Reinecke BN, Jaramillo TF. Engineering the Surface Structure of MoS2 to Preferentially Expose Active Edge Sites for Electrocatalysis. Nat. Mater. 2012;11:963969. PMID: 23042413. Available from: https://doi.org/10.1038/ nmat3439. 
15. Deng J, Li H, Wang S, Ding D, Chen M, Liu C, Tian Z, Novoselov KS, Ma C, Deng D, Bao X. Multiscale Structural and Electronic Control of Molybdenum Disulfide Foam for Highly Efficient Hydrogen Production. Nat. Commun. 2017;8:14430. PMID: 28401882. Available from: https://doi.org/10.1038/ ncomms 14430 .

16. Bora $\mathrm{S}$, Jung GY, Sa YJ, Jeong HY, Cheon JY, Lee JH, Kim HY, Kim JC, Shin HS, Kwak SK, Joo SH. Monolayer-Precision Synthesis of Molybdenum Sulfide Nanoparticles and Their Nanoscale Size Effects in the Hydrogen Evolution Reaction. ACS Nano. 2015;9:3728-3739. PMID: 25794552. Available from: https: //doi.org/10.1021/acsnano.5b00786.

17. Yu Y, Huang S-Y, Li Y, Steinmann SN, Yang W, Cao L. Layerdependent Electrocatalysis of MoS2 for Hydrogen Evolution. Nano Lett. 2014;14:553-558. PMID: 24397410. Available from: https://doi.org/10.1021/nl403620g

18. Cwik S, Mitoraj D, Mendoza Reyes O, Rogalla D, Peeters D, Kim J, Schütz HM, Bock C, Beranek R, Devi A. Direct Growth of MoS2 and WS2 Layers by Metal Organic Chemical Vapor Deposition. Adv. Mater. Interfaces. 2018;5(1800140):1-11. Available from: https://doi.org/10.1002/admi.201800140.

19. Verble JL, Wieting TJ. Lattice Mode Degeneracy in MoS2 and Other Layer Compounds. Phys. Rev. Lett. 1970;25:362-365. Available from: https://doi.org/10.1103/PhysRevLett.25.362.

20. Zeng H, Zhu B, Liu K, Fan J, Cui X, Zhang QM. Low-frequency Raman Modes and Electronic Excitations in Atomically Thin MoS2 Films. Phys. Rev. B. 2012;86:241301. Available from: https://doi.org/10.1103/PhysRevB.86.241301.

21. Wang $X$, Feng $\mathrm{H}, \mathrm{Wu} \mathrm{Y}$, Jiao L. Controlled Synthesis of Highly Crystalline MoS2 Flakes by Chemical Vapor Deposition. J. Am. Chem. Soc. 2013;135:5304-5307. PMID: 23489053. Available from: https://doi.org/10.1021/ja4013485.

22. Lin YC, Zhang W, Huang JK, Liu KK, Lee YH, Liang CT, Chu CW Li LJ. Wafer-scale MoS2 Thin Tayers Prepared by MoO3 Sulfurization. Nanoscale. 2012;4:6637-6641. PMID: 22983609. Available from: https://doi.org/10.1039/c2nr31833d.

23. Ahn C, Lee J, Kim HU, Bark H, Jeon M, Ryu GH, Lee Z, Yeom GY, Kim K, Jung J, Kim Y, Lee C, Kim T. Low-Temperature Synthesis of Large-Scale Molybdenum Disulfide Thin Films Directly on a Plastic Substrate Using Plasma-Enhanced Chemical Vapor Deposition. Adv. Mater. 2015;27:5223-5229. PMID: 26257314 Available from: https://doi.org/10.1002/adma.201501678.

24. McCrory CC, Jung S, Ferrer IM, Chatman SM, Peters JC, Jaramillo TF. Benchmarking Hydrogen Evolving Reaction and Oxygen Evolving Reaction Electrocatalysts for Solar Water Splitting Devices. J. Am. Chem. Soc. 2015;137:4347-4357. PMID: 25668483. Available from: https://doi.org/10.1021/ ja510442p.

25. Wang $\mathrm{H}$, Tsai $\mathrm{C}$, Kong D, Chan K, Abild-Pedersen F, Nørskov JK, Cui Y. Transition-metal Doped Edge Sites in Vertically Aligned MoS2 Catalysts for Enhanced Hydrogen Evolution. Nano Res. 2015;8:566-575. Available from: https://doi.org/10. 1007/s12274-014-0677-7.

26. Ye G, Gong $Y$, Lin J, Li B, He Y, Pantelides ST, Zhou W, Vajtai R, Ajayan PM. Defects Engineered Monolayer MoS2 for Improved Hydrogen Evolution Reaction. Nano Lett. 2016;16:1097-1103. PMID: 26761422. Available from: https: //doi.org/10.1021/acs.nanolett.5b04331.

27. Shokhen V, Zitoun D. Platinum-Group Metal Grown on Vertically Aligned MoS2 as Electrocatalysts for Hydrogen Evolution Reaction. Electrochimica Acta. 2017;257:49-55. Available from: https://doi.org/10.1016/j.electacta.2017.10.014. 